\title{
A ação coletiva como instrumento de transformação urbana e sua presença no território periférico de São Paulo'
}

\section{Collective action as an instrument of urban transformation and its presence in the peripheral territory of São Paulo}

\author{
Carvalho, Liliane Katita'; Imbronito, Maria Isabel2; \\ 1 Universidade São Judas Tadeu, Av. João XXIII, 883, São Paulo -SP, 03361-000, \\ Brasil, lilianekcarvalho@gmail.com \\ 2 Universidade São Judas Tadeu, imbronito@gmail.com
}

\begin{abstract}
RESUMO
A acentuação de organizações horizontais mobilizadas para o enfrentamento de questões aderidas ao território em que se habita, implementadas principalmente através dos avanços das tecnologias de informação e comunicação, implica no surgimento de uma potência que se exponencia pela ação coletiva. Um desdobramento possível desse fenômeno contemporâneo é o que se poderia chamar rede tática, na qual ações complementares de coletivos urbanos são estruturadas de modo flexível e rizomático. Através do conceito de urbanismo tático é possível discutir desdobramentos do incremento das ações coletivas em rede, que poderá alterar o status qualitativo do entendimento da sociedade perante a construção do território e o próprio significado do corpo social. Esta pesquisa, ainda em andamento, limita-se a investigar a existência ou não de uma rede tática no Distrito de São Mateus, São Paulo, através da produção e análise de mapeamentos que buscam sintetizar as formas de intervenção no território, produzidas pela ação dos coletivos urbanos. A escolha pelo Distrito deu-se em função de um histórico de ações reivindicatórias por condições de moradia e serviços que estão relacionadas ao processo de urbanização da região. A investigação desenvolveu-se da identificação de coletivos e ações locais, e da indagação sobre sua articulação e ação conjunta.
\end{abstract}

Palavras-chave: Ação coletiva, coletivos urbanos, periferia.

\begin{abstract}
The accentuation of horizontal organizations mobilized to deal with issues adhering to the territory in which they live, implemented mainly through the advances of information and communication technologies, implies the emergence of a power that is exponentiated by collective action. A possible unfolding of this contemporary phenomenon is what might be called a tactical network, in which complementary actions of urban collectives are structured in a flexible and rhizomatic way. Through the concept of tactical urbanism, it is possible to discuss unfolding of the increase of collective actions in a network, which could alter the qualitative status of the understanding of society before the construction of the territory and the very meaning of the social body. This research, still in progress, is limited to investigate the
\end{abstract}

${ }^{1}$ CARVALHO, Liliane Katita; IMBRONITO, Maria Isabel. A ação coletiva como instrumento de transformação urbana e sua presença no território periférico de São Paulo. In: II SIMPÓSIO NACIONAL DE GESTÃO E ENGENHARIA URBANA: SINGEURB, 2019, São Paulo. Anais... Porto Alegre: ANTAC, 2019. 
existence or not of a tactical network in the District of São Mateus, São Paulo, through the production and analysis of mappings that seek to synthesize the forms of intervention in the territory, produced by the action of the urban collectives. The District's choice was based on a history of claims for housing conditions and services that are related to the process of urbanization in the region. The investigation was developed of the identification of collective and local actions, and of the inquiry about their articulation and joint action.

Keywords: Collective action, urban collectives, periphery.

\section{EXPERIÊNCIAS COLETIVAS E A CONSTRUÇÃO DA CIDADE}

O campo do urbanismo, anteriormente restrito ao planejamento enquanto programação funcional e ao projeto enquanto desenho definidor de relações espaciais e sociais, tem se estendido, desde o final dos anos 1950, de modo a abranger a participação e a ação popular nas definições do espaço em que se vive. Esse entendimento, de certa forma, contrapõe o urbanismo oficialmente produzido, enquanto ações do estado e do mercado, ao urbanismo do século XXI, dividido entre o envolvimento da sociedade no planejamento oficial, através de instâncias participativas ou manifestações espontâneas que respondem à agenda oficial, e a ação cotidiana popular transformadora da realidade em seus aspectos físicos, culturais e de prestação de serviços.

As problemáticas surgidas a partir do processo de crescimento e ocupação urbana das cidades brasileiras no século XX, tornaram-se fatores propulsores para as insurgências reivindicatórias que lutavam pela transformação do espaço urbano e pela melhoria da condição social das pessoas nas cidades brasileiras. Buscava-se encontrar formas de estabelecer mudanças sociais que pudessem diminuir as desigualdades promovidas pela herança do processo de formação desigual que se espalhou pelas cidades brasileiras, mais notoriamente por seus territórios periféricos.

Localmente, dada a conjuntura histórico-política brasileira e a entrada dos parâmetros neoliberais, nos anos 1990, tornou-se possível observar não só transformações no processo produtivo, na gestão e organização do trabalho, mas, também no espaço construído, acentuando ainda mais os contrastes socioculturais (VAINER, 2000). Para Dardoł e Laval (2016), pode-se entender o neoliberalismo como uma racionalidade2, "pois (o neoliberalismo) estrutura não só as formas de governança, como também a conduta dos governados, superando a ideia de fundamentá-lo apenas como uma política econômica" (2016, p.17). Para os autores, trata-se de uma lógica que influencia as relações de poder em diversos aspectos da vida política, econômica e social, e que possui força para exercer influência global, atuando em diferentes escalas na sociedade.

Tal virada neoliberal acentuou as disparidades durante a expansão urbana das grandes cidades brasileiras e as reivindicações por melhoramentos nas condições de vida tornaramse ferramentas de ação sociopolítica nos territórios periféricos destas cidades (MARICATO, 2014). Com o avanço político e social no Brasil, concomitante à revolução tecnológica e o uso das redes sociais, as articulações dos movimentos sociais passaram a apresentar ramificações, abrindo espaços à novas frentes de discussões e reivindicações de como ocupamos e vivemos a cidade (HARVEY, 2014). Essas articulações buscam modos de compreender como a lógica hegemônica afeta o território, e pautam-se na contiguidade e solidariedade para constituir resistências a partir do território habitado.

\section{AÇÃO TÁTICA COMO FORMA DE RESISTÊNCIA}

Insurgências urbanas e manifestações sociais contemporâneas buscam reestruturar, através de suas lutas, novos meios para o enfrentamento das problemáticas encontradas na vivência

\footnotetext{
2 Para aprofundar-se no tema neoliberalismo como uma racionalidade ver mais em Dardot, P.; Laval, C. A nova razão do mundo: Ensaio sobre a sociedade neoliberal. (São Paulo: Boitempo, 2016).
} 
das cidades, consolidando-se, entre eles, o próprio urbanismo tático e outras ações coletivas desenvolvidas sob parâmetro conceitual semelhante.

Pode-se afirmar que, na última década, as ações difundidas através do urbanismo tático (LYDON; GARCIA, 2000) foram potencializadas por conta do contexto de crise urbana global, que articulou componentes como "o rápido crescimento populacional, a reestruturação da produção industrial, a má adequação das infraestruturas físicas urbanas e a polarização das classes sociais" (BRENNER, 2016, p.1). Essas tensões, em conjunto, intensificaram a falta de representatividade política, culminando em inúmeros levantes reivindicatórios por diversas cidades do Brasil e do mundo que, potencializados pelo avanço da tecnologia e das redes digitais, criaram um contexto favorável a disseminação do Urbanismo Tático como solução paliativa às problemáticas urbanas resultantes dos períodos modernistas-estatistas e neoliberalistas.

Torna-se importante destacar, nos anos de 1990, a chamada revolução da tecnologia da informação. Castells (2002) afirma que a revolução tecnológica estabeleceu um novo padrão nas bases da economia, sociedade e cultura, formalizando novos meios de produção, de divisão do trabalho e da comunicação, ambos condicionados por um amplo sistema de redes. Na comunicação, destaca-se o potente avanço das TIC's (Tecnologia da Informação e da Comunicação) que, através da extensão e utilização da internet, viabilizou o surgimento de sistemas de comunicação por meio de redes virtuais e via satélite, estabelecendo novas formas de relacionamento social e comportamental.

Para entender a produção da ação coletiva como um elemento integrador das relações estabelecidas no território de estudo, considera-se, neste artigo, o termo ação coletiva como ações pontuais, de baixo custo e de curto prazo, baseiam-se no urbanismo tático ou "urbanismo de guerrilha" (PETRESCU, 2013). As ações coletivas são promovidas através de grupos autogeridos, organizados de modo flexível e anárquico, mobilizados de baixo para cima, conhecidos atualmente por 'coletivos urbanos' (MAZIVIERO, 2016). São capazes de fomentar intenções e/ou ações políticas que interferem em questões da cidade, sejam elas urbanas ou sociais, além de fomentar a promoção de mudanças positivas na maneira de viver as ruas, os bairros e as cidades.

Estas iniciativas apresentam diversas características. Destaca-se a oposição às formas de planejamento tradicionais, realizada principalmente através da proposição das intervenções urbanas idealizadas coletivamente, sem um controle governamental e de forma horizontal. As ações também:

Podem ser vistas como microrresistências urbanas - têm o objetivo de ocupar, apropriar-se do espaço público para construir e propor outras experiências sensíveis e, assim, perturbar essa imagem tranquilizadora e pacificado do espaço público que o espetáculo do consenso tenta forjar (JACQUES, 2011, p.172).

\section{DISTRITO DE SÃO MATEUS: INSURGÊNCIA DE UMA REDE TÁTICA}

O distrito de São Mateus fica localizado na Zona Leste da cidade de São Paulo, como parte da franja periférica sudeste da cidade e, dista aproximadamente 22 quilômetros da região central da cidade de São Paulo. Atualmente, as ações coletivas desenvolvidas no Distrito abordam questões que ajudam no desenvolvimento cultural e social da área, como por exemplo, o cultivo de hortas e alimentos orgânicos, o desenvolvimento de cultura e arte, mobilização comunitária, além do avanço na conscientização sociopolítica dos moradores, sobre a ocupação do território, em seus diversos aspectos.

A partir do mapeamento de coletivos urbanos e ações táticas realizado pelo Grupo de Estudo CNPQ "Urbanismo na Era Digital", pode-se apresentar um recorte da atual situação das atividades desenvolvidas na área estudo, onde foram identificados quatorze coletivos. 
Figura 1 - Coletivos Mapeados no Distrito de São Mateus

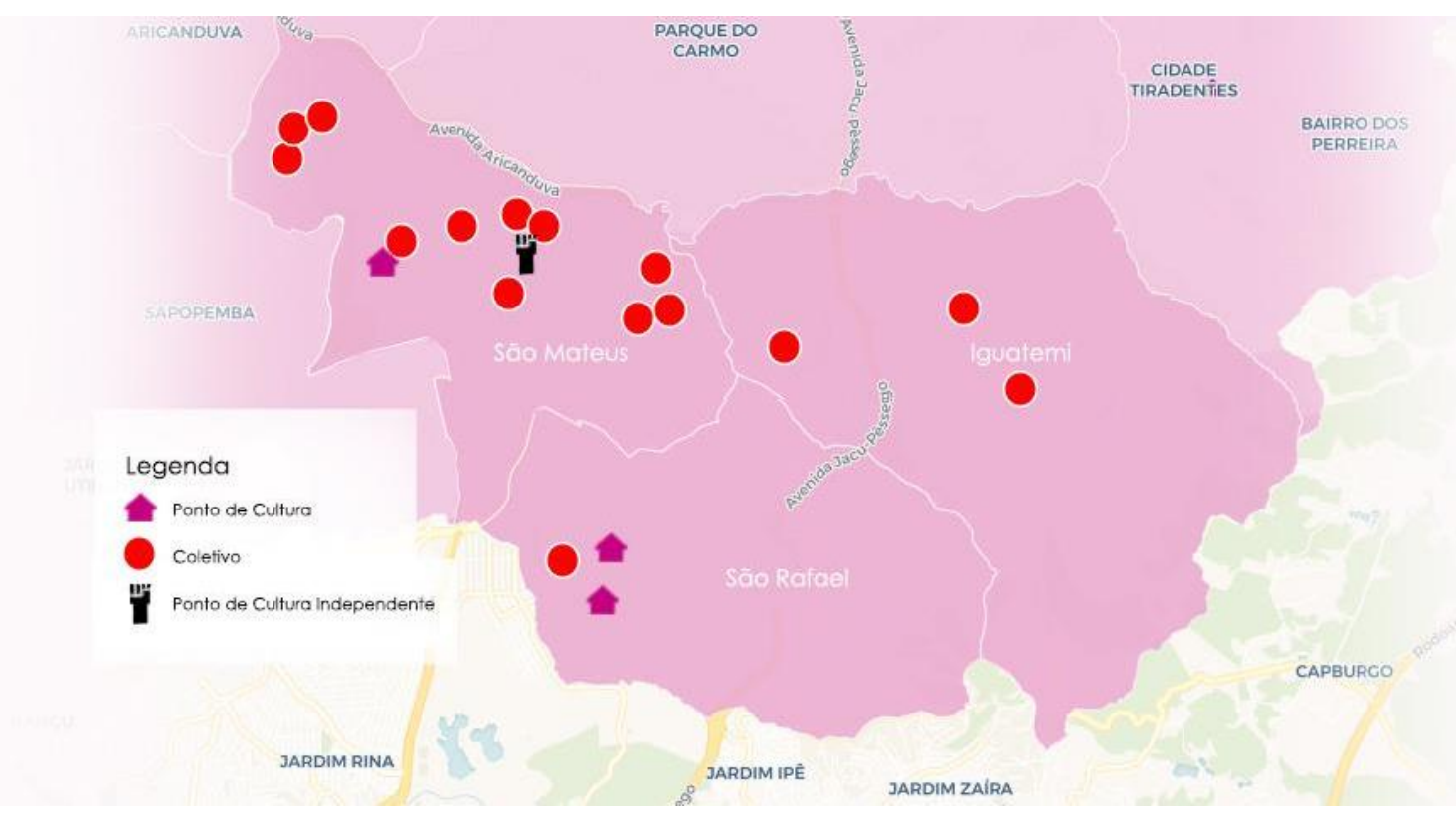

Fonte: Elaboração própria com base no Mapeamento do Grupo de Pesquisa "Urbanismo na Era Digital", os dados estão disponibilizados para consulta pública em: https://goo.gl/V5ql4Y.

Durante o mapeamento, realizou-se a classificação dos grupos seguindo critérios de análise estabelecidos pelo Grupo de Pesquisa citado, a partir da observação e acompanhamento das atividades, dividindo-os entre:

- Coletivos: grupos com ações específicas;

- Ponto de cultura: espaço coletivo oficializado pelo poder público;

- Rede de compartilhamento: grupos que reúnem outros coletivos a fim de compartilhar informações;

- Ponto de cultura independente: espaço coletivo não oficializado pelo poder público.

Além disso, classificou-se suas ações entre:

- Itinerantes;

- fixos.

E seus campos de atuação, dividindo-os entre:

- Fortalecimento da cultura periférica;

- Artes Visuais/Grafitti;

- Música/teatro/literatura;

- Agricultura urbana;

- Atividade Cultural;

- Empoderamento Feminino.

Ao compararmos o contexto dos coletivos da área de estudo, é possível identificar similaridades nos objetivos das ações táticas desenvolvidas por eles. Estas similaridades criam conexões entre as ações, encontrando propósitos comuns entre os grupos. Através do avanço dos meios de comunicação, a rede tática se fortalece tanto na realidade virtual, através das redes sociais onde seus pares se encontram reforçando uma ideia ou propósito, como na própria utilização do espaço urbano, seja por ocupação fixa e constante ou itinerante de caráter provisório.

De acordo com Castells (2013), as conexões em rede podem se dar de diversas formas, incluindo redes preexistentes ou rede formadas durante ações ou conexões sejam elas virtuais ou reais, on-line ou off-line, formando redes dentro de redes. Pode-se observar, nos coletivos, conexões que não são realizadas somente por um ponto fixo ou em uma única direção. Essas 
conexões podem ser consideradas como rizomas (Deleuze, 1997), que são estruturas flexíveis que em qualquer ponto pode ser conectado a outro, num esquema horizontal e não vertical.

Nos coletivos observados, percebe-se que a coalizão dos interesses de indivíduos envolvidos nas ações táticas cria aberturas que podem ser consideradas ramificações na leitura da rede tática. Elas vinculam novos atores e ações a coletivos que detém uma maior estabilidade como os pontos de cultura. Para entender a estruturação dessa rede, estuda-se a concepção de uma proposta metodológica que seja capaz de analisar as relações constituídas pela rede de ação tática observada dentro do território de estudo, analisando seus atores, condições e contexto.

Esses novos agenciamentos abrangem as novas ferramentas que se infiltram nos processos de desenvolvimento neoliberal, que atingem territórios de maior vulnerabilidade como a área estudo. Isso demonstra o potencial implícito dessas ações na transformação do território, na expansão da produção do comum, e por consequência na construção de novas formas de gerir o espaço urbano de maneira compartilhada e coletiva.

Destaca-se que a organização política dos coletivos não se estrutura em formas fixas, mantendo suas relações abertas, considerando as singularidades de cada demanda e incorporando a multiplicidade de diferenças em seu processo. Desta forma é possível afirmar que esta organização se justapõe ao conceito de multidão estabelecido por Hardt e Negri (2005). Os autores propõem que multidão, diferente de 'massa' entendida como algo uniforme, e 'povo' como uma identidade, é composta de inúmeras diferenças internas, e por isso não é possível reduzi-la a uma identidade única. A multidão é um conceito aberto que atua em um mundo onde a produção em termos gerais, já não é percebida apenas em termos econômicos e sim de uma forma mais ampla, apresentada como produção social, cuja composição abarca "a produção de comunicações, relações e formas de vida" (HARDT; NEGRI, 2005, p.13).

\section{CONSIDERAÇÕES FINAIS}

A partir do que foi apresentado, podemos fomentar a discussão sobre a efetividade das ações coletivas no planejamento urbano local e gestão do território periférico. O papel dos atores envolvidos nestas ações é fundamental para entendermos sua lógica. Os ativistas periféricos executam uma espécie de mediação sobre seu território e o poder público, demonstrando a partir da apropriação política do espaço urbano a relevância do direito à cultura, ao meio ambiente e aos espaços públicos para se viver a cidade.

Esse trabalho de conscientização se difere na periferia, pois causa um impacto social muito significativo, capaz de promover mudanças no território, com melhoria urbana, estética e política. Trata-se de uma prática que altera a dinâmica da ordem democrática e, por isso, suscita novos arranjos nas relações sociopolíticas. A ação coletiva entra como uma medida mitigadora da vulnerabilidade ampliada pela lógica neoliberal no desenvolvimento das cidades e, no território periférico, as ações realizadas em curto prazo podem persistir na paisagem urbana por um longo prazo, tornando-se referências a outras práticas insurgentes, como as ações mapeadas no do Distrito de São Mateus.

\section{REFERÊNCIAS}

BRENNER, Neil. Seria o "urbanismo tático" uma alternativa ao urbanismo neoliberal? Revista EMetrópolis, ano 07, $n^{\circ}$ 27, 2016. Disponível em: <http://emetropolis.net/edicao/n27>. Acesso em 01-11-2018.

CASTELLS, Manuel. A Sociedade em Rede. Rio de Janeiro: Bertrand Brasil, 2002.

Redes de Indignação e Esperança: Movimentos Sociais na era da internet. led. - Rio de Janeiro: Zahar, 2013.

DARDOT, Pierre; LAVAL, Christian. A nova razão do mundo: ensaio sobre a sociedade 
neoliberal. 1. ed. São Paulo: Boitempo, 2016.

DELEUZE, Gilles e GUATTARI, Félix. 1995-1997. Mil Platôs: Capitalismo e Esquizofrenia. Rio de Janeiro: Editora 34. 715 pp.

HARVEY, David. Cidades Rebeldes: Do direito à cidade à revolução urbana. São Paulo: Martins Fontes, 2014.

HARDT, Michael; NEGRI, Antonio. Multidão: guerra e democracia na era do Império. Rio de Janeiro: Record, 2005. 530p.

JACQUES, Paola B. Microrresistências urbanas: Por um urbanismo incorporado.In: ROSA, Marcos L. Microplanejamento Urbano: Práticas Urbanas Criativas. São Paulo: Editora de Cultura, 2011.

LYDON, Mike; GARCIA, Anthony. Tactical Urbanism. Washington:Island Press, 2000.

MARICATO, Erminia. O impasse da política urbana no Brasil. 3. Ed. - Petrópolis, RJ: Vozes, 2014.

MAZIVIERO, Maria Carolina. Urbanismo insurgente: modo alternativo de produção e apropriação de espaços públicos na periferia de São Paulo. The 17th International Planning History Society Conference - Delft, July 2016

PETRESCU, Javier Vergara. Qué es el Urbanismo Táctico? In: STEFFENS, Kurt; et al. Urbanismo Táctico 3: Casos Latinoamericanos. Ciudad Emergente. 2013. p.13-17.

VAINER, C. B. Pátria, empresa e mercadoria. Notas sobre a estratégia discursiva do planejamento estratégico urbano. In: ARANTES, O. MARICATO, E. VAINER, C.B. A cidade do pensamento único: desmanchando consensos. Petrópolis: Vozes, 2000. p. 169-221. 